\title{
Transições para a sustentabilidade na agricultura corporativa: inovação agroecológica na viticultura do Douro, Portugal
}

\author{
Transitions Towards Sustainability in Corporate Agriculture: \\ agro-ecological innovation in Douro viticulture, Portugal \\ Fabíola Polita1 (1D, Livia Madureira ${ }^{10}$
}

${ }^{1}$ Centro de Estudos Transdisciplinares para o Desenvolvimento (CETRAD), Programa de Doutoramento em Desenvolvimento, Sociedades e Territórios, Universidade de Trás-os-Montes e Alto Douro (UTAD), Vila Real, Portugal. E-mails: al67677@utad.eu; Imadurei@utad.pt

\begin{abstract}
Como citar: Polita, F., \& Madureira, L. (2022). Transições para a sustentabilidade na agricultura corporativa: inovação agroecológica na viticultura do Douro, Portugal. Revista de Economia e Sociologia Rural, 60(2), e236238. https://doi.
\end{abstract} org/10.1590/1806-9479.2021.236238

Resumo: O objetivo deste artigo é aplicar a Multi Level Perspective (MLP) a um caso de transição para a sustentabilidade da agricultura que ocorre a partir do desenvolvimento de uma inovação agroecológica. À perspectiva temporal e multinível dada pela MLP, conjugamos o conceito de Agricultural Knowledge and Innovation Systems (AKIS), com a intenção de conciliar uma dimensão territorial para a análise. O cenário empírico é a região vitivinícola do Douro, em Portugal, na qual se disseminou uma inovação denominada Infraestrutura Ecológica (IE). Metodologicamente, fizemos entrevistas pessoais estruturadas, realizadas com agricultores ou gestores agrícolas, representantes de explorações comerciais de uva e vinho. Constatamos que há um princípio de transição liderado por agricultores corporativos que comercializam no mercado global. Este princípio de transição está alicerçado na mobilização de um AKIS territorial que permitiu o desenvolvimento do arcabouço cognitivo e técnico que estruturou o setor para sua articulação às demandas de mercado. Entretanto, este AKIS não é igualmente mobilizado pelos diferentes agricultores, o que se manifesta em distintas respostas de adoção da inovação. O caso explicita como as pressões de paisagem sociotécnica, representada pelo mercado, podem criar diferentes respostas no regime local.

Palavras-chave: viticultura, Douro, Portugal, transições para a sustentabilidade, MLP (Multi Level Perspective), AKIS (Agricultural Knowledge and Innovation Systems).

\begin{abstract}
The objective of this article is to apply the Multi Level Perspective (MLP) to a transition case of agricultural sustainability that occurs from the development of an agroecological innovation. To the temporal and multilevel perspective given by MLP, we conjugate the concept of Agricultural Knowledge and Innovation Systems (AKIS), with the intention of reconciling a territorial dimension to the analysis. The empirical setting is the Douro wine region in Portugal, in which an innovation denominated Ecological Infrastructure (El) has been disseminated. Methodologically, we conducted structured personal interviews with farmers or farm managers, representatives of commercial grape and wine farms. We found that there is a transition principle led by corporate farmers who trade in the global market. This transition principle is grounded in the mobilization of a territorial AKIS that allowed the development of the cognitive and technical framework that structured the sector for its articulation to market demands. However, this AKIS is not equally mobilized by the different farmers, which manifests itself in different innovation adoption responses. The case makes it clear how sociotechnical landscape pressures, represented by the market, can create different responses in the local regime.
\end{abstract}

Keywords: viticulture, Douro, Portugal, transitions towards sustainability, MLP (Multi Level Perspective), AKIS (Agricultural Knowledge and Innovation Systems).

\section{Introdução}

Nas próximas décadas, o setor agrícola terá de prover alimentos e matérias-primas para uma população mundial crescente e cujos padrões de consumo vêm se alterando 
(Bais-Moleman et al., 2019). Mas, se por um lado o cenário agrícola exigirá maior produtividade e competitividade, por outro, demandará por inovações que visem uma transição a quadros mais sustentáveis, incluindo a redução do desperdício alimentar. Estas inovações, por sua vez, estarão alicerçadas em conhecimentos novos e transdisciplinares (Coughenour, 2003; Ingram, 2008).

Neste artigo apresenta-se um caso em que um grupo de agricultores foi capaz de dinamizar estruturas de conhecimento que lhes dessem aporte para iniciar um processo de transição para a sustentabilidade da agricultura por eles praticada, criando um sistema intensivo em aprendizagem agroecológica adaptado às suas condições sociais específicas. Estes agricultores, especializados na produção da uva e vinho, estão dispostos na zona vitivinícola demarcada que circunvizinha o Rio Douro, no Norte de Portugal. Estão organizados em estruturas de agricultura familiar comercial e empresarial e vêm incorporando às suas práticas agrícolas uma série de manejos agroecológicos denominados de Infraestruturas Ecológicas (IE). As IEs consistem em conjugações das linhas e áreas de videiras com outras vegetações auxiliares, nativas ou exóticas, com o objetivo de ampliar os serviços ecossistêmicos das áreas de cultivo, uma vez que a zona tem também importância no que diz respeito à biodiversidade. $O$ caso torna-se peculiar porque a introdução das IEs teve sua origem já em meados de 2010, o que garante, portanto, certa rastreabilidade do percurso da inovação. Além do mais, retrata uma inovação agroecológica fomentada em um contexto empresarial e comercial que evidencia que a agroecologia também pode emergir como resposta de pressões de mercado.

Objetiva aplicar a Perspectiva Multinível (Multi Level Perspective, para a qual usaremos, deste ponto em diante, a sigla MLP), na compreensão de como se processam as dinâmicas de inovação para a transição da agricultura sustentável em um contexto regional. Nota-se que a transição observada está centrada em casos de agricultura comercial e empresarial e que a inovação, de cunho agroecológico e sustentável, neste caso converte-se em estratégia de comercialização e inserção mercadológica do produto agrícola cuja diferenciação, pela via agroecológica, torna-o competitivo num mercado global onde existem nichos que valorizam este tipo de diferenciação.

A MLP permite analisar o percurso de uma inovação a partir de elementos sociotécnicos da própria inovação e do ambiente no qual ela se insere. Esta perspectiva, que se desenvolveu a partir da Teoria da Transição (Rip \& Kemp, 1998), possibilita que se trate de uma inovação a partir de uma perspectiva temporal. Ao ter em vista, entretanto, que a MLP visualiza os percursos das inovações por seus componentes sociais e técnicos, e que as inovações na agricultura podem envolver especificidades que vão para além destas componentes, faz-se interessante conjugar a MLP a outras perspectivas de análise, já que tratamos aqui de uma inovação de cunho agroecológico, fortemente embasada em aspectos territorializados (como são aspectos sociais e ecológicos, por exemplo) (Duru et al., 2015). Por isso, congregamos também uma concepção regionalizada da inovação, proporcionada pelos Sistemas de Inovação e Conhecimento (Agricultural Knowledge and Innovation Systems - AKIS), que oferecem uma análise da evolução das inovações a partir de trocas de aprendizagens e conhecimentos entre atores de um contexto específico.

Neste artigo, assim, apresentamos, na seção 1, a fundamentação teórica, envolvendo as subseções 1.1) A Teoria da Transição para a sustentabilidade pelo uso da MLP aplicada ao caso da agricultura, e subseção 1.2) Transições à agricultura sustentável e sua relação com contextos sistêmicos e socioecológicos. A seção 2 comporta a metodologia empregada no estudo. $\mathrm{Na}$ seção 3, trazemos os resultados e discussões do artigo, composto pelas as subseções 3.1) Apresentação do caso estudado, e 3.2) O caso da transição da viticultura do Douro à luz dos conceitos norteadores. Na seção 4, as conclusões. 


\section{Fundamentação teórica}

\subsection{A Teoria da Transição para a sustentabilidade pelo uso da MLP aplicada ao caso da agricultura}

As inovações podem desencadear processos de mudança ao promoverem rearranjos nos regimes sociotécnicos (Geels et al., 2008). Estes processos de mudança são chamados de transição (Hinrichs, 2014) e, cientificamente, vêm sendo tratados pela teoria que leva o mesmo nome (Teoria da Transição), desenvolvida por autores como Rip \& Kemp (1998), Smith (2003), Geels (2004), Moors et al. (2004) e Seyfang (2006).

Empiricamente, a Teoria da Transição pode ser operacionalizada por um esquema explicativo denominado Multi Level Perspective (MLP). A MLP mapeia o desenvolvimento de uma inovação a partir da dinâmica que se opera entre seus três níveis analíticos, de nicho, regime e paisagem, quando do surgimento e emergência de uma inovação. 0 primeiro, chamado de nicho, por definição, é o berço das inovações. Nos nichos é que as inovações são idealizadas, criadas e experimentadas e, quando atingem certo grau de desenvolvimento, podem sair deste para o segundo nível, que é o regime. É no regime que as inovações são efetivamente disseminadas pelos usuários. A paisagem é o nível que envolve os outros dois, e sua composição é ditada por variáveis contextuais de grande abrangência. Importante salientar que a MLP concebe o nicho, o regime e a paisagem por suas composições sociotécnicas. Na MLP, uma transição ocorre quando uma inovação consegue sucesso no nível do nicho, adentra ao regime sociotécnico e nele promove alterações (Geels, 2011; Vila Seoane \& Marín 2017).

A MLP consegue mostrar as transições a partir de interações entre os níveis esquemáticos (Sutherland et al., 2014), oferecendo também um aparato para explicar as transições a partir da conjugação de eventos com grande mobilidade (de nicho) a eventos com maior estabilidade (de regime) (Geels, 2020). A MLP, porém, foi desenvolvida para abordar transições de cunho tecnológico. Por esta razão, não contempla aspectos peculiares a outras transições, como são as da agricultura, que comportam particularidades ecológicas e socioeconômicas, por exemplo. Em razão do modo como que foi concebida, questões de agência e interações entre atores (Holtz et al., 2008), bem como fatores políticos, científicos, industriais, culturais e de mercados (Geels \& Schot, 2010), podem ficar subvalorizados nas análises. Como lembra Darnhofer (2015), nas transições da agricultura estas questões podem ter relevância, em razão destas últimas nem sempre serem impulsionadas pela tecnologia.

Isto justifica o fato de que em estudos empíricos a MLP tenha sido associada a diversas metodologias ou conjugação de métodos, com a finalidade de melhor explorar a pluralidade de aspectos envolvidos com as transições da agricultura. A Tabela 1 explora um conjunto de artigos científicos que mostra a diversidade de investigações desenvolvidas em várias partes do mundo, com maior profusão a partir do ano de 2015, em que se aplica a Teoria da Transição. Os estudos também explicitam o uso da MLP, ou, em alguns casos, apenas mencionam a terminologia de "nicho", "regime" e/ou "paisagem" no tratamento dos casos, que podem ter amplitude nacional ou regional, ainda que sejam escassos os estudos que aplicam a teoria à escala regional. 
Tabela 1 - Aplicações da MLP a estudos empíricos nas transições sociotécnicas na agricultura.

Autores Ano Caso estudado Escala de estudo

1. Elzen, Van Mierlo 2012 Procura explicar os processos de ligação entre

e Leeuwis

nichos e regimes por meio do estudo do caso

Nacional

holandês de redução do consumo energético

relacionado ao cultivo de hortícolas em

estufas.

2. Feola, Lerner e Jain

2015 Estuda o comportamento de tomada de decisão de agricultores, em adotar, ou não, determinadas inovações, em cinco distintos pontos do mundo: México Central; Andes colombianos; Noroeste da Califórnia; Gujarat, na Índia, e Filipinas.

3. Konefal

4. Ramani e Thutupalli

5. Bui, Cardona e Lamine

6. Sherwood, Van Bommel e Paredes

7. Anjos e Caldas

8. Hansen e Bjørkhaug

9. Isgren e Ness Cazella

11. von Oelreich e Milestad
10. Medeiros e
2015 Trata da lacuna existente na literatura científica a respeito do papel que a governança exerce nas transições para a sustentabilidade na MLP, nos EUA.

2015 Estuda a mediação do governo em duas transições que se operaram na Índia: produção de algodão durante o período da Revolução Verde e introdução do algodão $\mathrm{BT}^{1}$.

2016 Analisa a ligação entre nichos e regimes, observando quatro iniciativas relacionadas ao setor agroalimentar, na França, que podem ser consideradas nichos.

2016 Estuda dificuldades e limitações envolvendo a questão política para a transição sociotécnica sustentável que se passa no Equador.

2017 Aborda consequências políticas de um caso inovador em torno de uma AFN (Alternative Food Network) italiana, chamada GAS (Gruppi di Acquisto Solidale).

2017 Discute as expectativas norueguesas com relação ao desenvolvimento de uma bioeconomia.

2017 Analisa a agroecologia como um nicho sociotécnico na Uganda.

2017 Investiga a criação de redes interinstitucionais como inovações (novidades), exemplificado pelo caso da COOMAFITT, cooperativa de agricultores familiares no litoral Norte do Rio Grande do Sul, Brasil.

2017 Analisa o papel de movimentos alternativos nas transformações do regime. Toma como exemplo dois casos de agricultura orgânica 3.0, na Suécia.
Variável para cada estudo, abrangendo desde a escala de comunidades até a escala de aldeias.

Nacional

Nacional

Regional

Estudo centrado na região de Carchi, nos Andes equatorianos.

Nacional

Nacional, com enfoque multissetorial.

Nacional

Caso regional, cuja transformação

foi favorecida por políticas nacionais.

Regional, defendendo que iniciativas orgânicas individuais podem contribuir para mudar o nicho orgânico e todo o sistema alimentar para a sustentabilidade.

Referências: Elzen et al. (2012), Feola et al (2015), Konefal (2015), Ramani \& Thutupalli (2015), Bui et al. (2016) Sherwood et al. (2016), Anjos \& Caldas (2017), Hansen \& Bjørkhaug (2017), Isgren \& Ness (2017), Medeiros \& Cazella (2017), von Oelreich \& Milestad (2017), Vila Seoane \& Marín (2017), Harchaoui \& Chatzimpiros (2019), Hassink et al. (2018), Nygaard \& Bolwig (2018), Roberts \& Geels (2019) e De Alban et al. (2019).

${ }^{1}$ BT, de Bacillus thurigiensis, espécie da qual se extraiu o gene de resistência aos herbicidas empregados na tecnologia das culturas geneticamente modificadas. 
Tabela 1 - Continuação...

\begin{tabular}{|c|c|c|c|}
\hline Autores & Ano & Caso estudado & Escala de estudo \\
\hline $\begin{array}{l}\text { 12. Vila Seoane e } \\
\text { Marín }\end{array}$ & 2017 & $\begin{array}{l}\text { Mostra a fragilidade de experiências de } \\
\text { agricultura que atuam contra a lógica do sistema } \\
\text { sociotécnico operante. Na Argentina, tratando } \\
\text { do nicho da apicultura orgânica desenvolvida } \\
\text { por uma cooperativa. }\end{array}$ & $\begin{array}{l}\text { Regional, mas usa o } \\
\text { caso como exemplo } \\
\text { para o nível nacional. }\end{array}$ \\
\hline $\begin{array}{l}\text { 13. Harchaoui e } \\
\text { Chatzimpiros }\end{array}$ & 2019 & $\begin{array}{l}\text { Associa a transição sociotécnica da agricultura } \\
\text { francesa à eficiência de uso de energia e } \\
\text { nitrogênio à geração de excedentes, nos últimos } \\
30 \text { anos. }\end{array}$ & Nacional \\
\hline $\begin{array}{l}\text { 14. Hassink, Grin e } \\
\text { Hulsink }\end{array}$ & 2018 & $\begin{array}{l}\text { Estuda o caso de care farming em } \\
\text { desenvolvimento na Holanda, exemplificando } \\
\text { os desafios adicionais de uma transição que } \\
\text { engloba dois sistemas. }\end{array}$ & Nacional \\
\hline $\begin{array}{l}\text { 15. Nygaard e } \\
\text { Bolwig }\end{array}$ & 2018 & $\begin{array}{l}\text { Analisa drivers e trajetórias do investimento } \\
\text { privado estrangeiro na produção de } \\
\text { biocombustíveis em Gana. }\end{array}$ & Nacional \\
\hline 16. Roberts e Geels & 2019 & $\begin{array}{l}\text { Estuda dois casos nos quais os formuladores } \\
\text { de políticas do Reino Unido aceleraram as } \\
\text { transições. }\end{array}$ & Nacional \\
\hline 17. De Alban et al. & 2019 & $\begin{array}{l}\text { Investiga a dinâmica LUCC - Land use } \\
\text { and Land Cover Change - na região de } \\
\text { Tanintharyi (Myanmar) para compreender } \\
\text { transições em virtude do uso da terra } \\
\text { agrícola. }\end{array}$ & Regional \\
\hline
\end{tabular}

Referências: Elzen et al. (2012), Feola et al. (2015), Konefal (2015), Ramani \& Thutupalli (2015), Bui et al. (2016), Sherwood et al. (2016), Anjos \& Caldas (2017), Hansen \& Bjørkhaug (2017), Isgren \& Ness (2017), Medeiros \& Cazella (2017), von Oelreich \& Milestad (2017), Vila Seoane \& Marín (2017), Harchaoui \& Chatzimpiros (2019), Hassink et al. (2018), Nygaard \& Bolwig (2018), Roberts \& Geels (2019) e De Alban et al. (2019).

A Teoria da Transição, por meio da MLP, usada em conjugação a diversos métodos ou metodologias, vem sendo aperfeiçoada de modo a melhor descrever os processos e fenômenos múltiplos e complexos relacionados à transição da agricultura. As principais conjugações metodológicas e analíticas objetivam desvendar aspectos de fragilidade das transições da agricultura, bem como explicar principalmente questões de governança e política relacionadas a tais processos. Neste estudo, particularmente, a título de uso da MLP, e das análises decorrentes, admitiremos que o nicho de inovação esteja relacionado às propriedades agrícolas e instituições que fomentaram o desenvolvimento e disseminação das IEs; que o regime esteja delimitado pela vitivinicultura do Douro e que a paisagem envolvente seja o setor vitivinícola global.

\subsection{Transições à agricultura sustentável e sua relação com contextos sistêmicos e socioecológicos}

Em se tratando das transições da agricultura, Lamine et al. (2012) mencionam que o modelo sociotécnico da MLP não considera algumas peculiaridades, como a diversidade social envolvida, que extrapola o grupo de agricultores e incorpora outras redes. Esta ideia de que a Teoria da Transição e seu modelo estrutural da MLP, por si só, não permita revelar a complexidade dos processos de transição da agricultura, é reiterada por outros autores, como demonstrado na Tabela 2. 
Tabela 2 - Contributos à complementação teórica do modelo sociotécnico quando aplicado à agricultura.

Referências

Benoît et al. (2012)

Röling \& Jiggins (1994); Coughenour (2003);

Sutherland et al. (2012)

Coenen et al. (2012);

Hansen \& Coenen (2015)

Darnhofer (2015);

Pigford et al. (2018)

Duru et al. (2015)

\section{Contributos}

Para Benoît e colaboradores, o esquema sociotécnico não considera a dinâmica de interação entre o sistema agrícola, a paisagem agrícola e a gestão dos recursos naturais, revelando a necessidade de se incorporarem outros elementos de análise.

Para estes autores, as novas formas de fazer a agricultura que desencadearão transições dos sistemas agrícolas são dotadas de conhecimentos específicos pertinentes ao ambiente nos quais são desenvolvidos.

Estes cientistas consideram que os estudos de transição da agricultura também precisam levar em conta a envolvência de elementos biofísicos e ecológicos.

Estes autores lembram que ao ser a agricultura espacialmente locada, é afetada pela natureza das condições espaciais que, além dos aspectos culturais, valores e tradições, inclui condições naturais de solos, clima e ecossistema, fazendo com que cada transição seja específica de cada local. Duru e colegas congregaram os conceitos de sistema agrícola, de sistema socioecológico e de sistema sociotécnico, estruturando um quadro analítico que se aplica à compreensão do fenômeno da transição sob os prismas daquilo que ocorre em termos de produção agrícola, de gestão de recursos naturais e da dinâmica das inovações na agricultura. Concluem que o sistema palco das transições da agricultura, além de multinível, é também multiator e multidomínio. Multiator por considerar os relacionamentos entre indivíduos e as assimetrias de poder que ocorrem entre estes relacionamentos. Multidomínio por levar em conta que as questões de agroecologia englobam também outras áreas, como a forma de provisão de suprimentos e o manejo dos recursos naturais.

Os processos de transição da agricultura, então, são insuficientemente abordados pelo uso de uma única perspectiva, que pode refratar a real composição de todas as circunstâncias que se combinam e se sobrepõem para culminar em tais processos. Além disso, estas transições são também expressas como processos de aprendizagem, uma vez que os agricultores precisam: fazer experimentações que conduzam a novas soluções; ter conhecimentos da biologia de cada ambiente; construir conhecimento de seus próprios sistemas de cultivo e inovar em relação às suas experiências anteriores (Prost et al., 2018; Toffolini et al., 2017; Cristofari et al., 2018).

Knickel et al. (2009), por sua vez, defendem que estes processos de aprendizagem não ocorrem de forma individualizada, mas de maneira colaborativa, já que resultam de ações coletivas dependentes das estruturas sociais em que os inovadores se concentram. As características, competências e interesses do universo de atores e instituições presentes em determinado contexto geográfico também influenciam os processos de inovação e aprendizagem (Cooke et al., 1997; Asheim, 1999; Naghizadeh et al., 2015; Capello, 2017). Em outras palavras, as inovações surgem a partir de atividades de aprendizagem interativas, combinadas e compartilhadas entre diversas organizações que ocupam um espaço regional e um sistema de produção (Cooke et al., 1997; Doloreux, 2002).

Assim, ao alicerçar a inovação sobre interações e fluxos de conhecimento entre organizações, admite-se que ela também tenha um caráter sistêmico, e a ideia de AKIS permite justamente compreender como estas inter-relações acabam por influenciar a trajetória das inovações agroecológica das propriedades agrícolas, e vice-versa, como as estratégias das propriedades agrícolas podem desencadear transições em sistemas agrícolas regionais. Os AKIS identificam a existência de um sistema de conhecimento e inovação que é fruto de mecanismos sociais nos quais se expressa o aprendizado coletivo e a criatividade (European Union, 2012) e, assim, 
esta concepção pode mostrar as interferências dos fluxos de conhecimento e inovação no ambiente ocupado pelas propriedades agrícolas, e como estas se utilizam deste fluxo para definir suas estratégias de gestão.

\section{Metodologia}

A coleta de dados realizou-se entre meses de abril e outubro de $2018^{2}$, por meio de entrevistas pessoais estruturadas, realizadas com 42 agricultores ou gestores agrícolas, representantes de explorações comerciais de uva e vinho. Foram selecionados por conveniência, empregando amostragem não probabilística que se utilizou de cadeias de referência (Biernacki \& Waldorf, 1981; Vinuto, 2014) em quem um agricultor indicava outros possíveis entrevistados (conhecido como snowball). Entrevistamos tanto agricultores que adotam a inovação, quanto quem nunca a adotou ou quem tentou implementá-la e acabou por desistir. O número de entrevistados foi determinado pelo esgotamento de introdução de novas informações. No total, 24 entrevistados eram adotantes da inovação, 16 eram não adotantes e 2 eram desistentes. A Tabela 3 traz o perfil destes agricultores, em virtude de seu posicionamento em relação à inovação (se adotante, não adotante ou desistente); se gestor e/ou proprietário; sua faixa etária; seu grau de escolaridade; a área cultivada com vinhas e o tipo de negócio praticado (se envolve a comercialização de uvas, ou se também a produção de vinhos e oferta enoturística).

Tabela 3 - Perfil dos entrevistados, em virtude do posicionamento em relação à inovação.

\begin{tabular}{|c|c|c|c|}
\hline & Adotantes & Não adotantes & Desistentes \\
\hline $\begin{array}{l}\text { Número total de } \\
\text { entrevistados }\end{array}$ & 24 & 16 & 2 \\
\hline $\begin{array}{l}\text { Gestor e/ou } \\
\text { proprietário }\end{array}$ & $\begin{array}{l}58,3 \% \text { dos entrevistados } \\
\text { eram gestores }\end{array}$ & $\begin{array}{l}93,8 \% \text { dos entrevistados } \\
\text { eram os proprietários }\end{array}$ & $\begin{array}{l}\text { Ambos gestores e } \\
\text { proprietários }\end{array}$ \\
\hline Faixa etária & $\begin{array}{l}70,8 \% \text { dos entrevistados } \\
\text { têm entre } 31 \text { e } 50 \text { anos } \\
\text { de idade }\end{array}$ & $\begin{array}{l}62,5 \% \text { dos entrevistados } \\
\text { têm entre } 41 \text { e } 70 \text { anos } \\
\text { de idade }\end{array}$ & $\begin{array}{l}\text { Ambos entre } 41 \text { e } 50 \\
\text { anos de idade }\end{array}$ \\
\hline Escolaridade & $\begin{array}{l}91,7 \% \text { dos entrevistados } \\
\text { têm ensino superior }\end{array}$ & $\begin{array}{l}50 \% \text { dos entrevistados } \\
\text { têm ensino superior }\end{array}$ & $\begin{array}{l}\text { Ambos com ensino } \\
\text { superior }\end{array}$ \\
\hline $\begin{array}{l}\text { Área cultivada com } \\
\text { vinhas }\end{array}$ & Área média de 145,23 ha & Área média de 20,83 ha & Área média de 9,70 ha \\
\hline Comercialização & $\begin{array}{l}75 \% \text { comercializam } \\
\text { vinhos, } 50 \% \text { fazem } \\
\text { enoturismo }\end{array}$ & $\begin{array}{l}93,8 \% \text { comercializam } \\
\text { uvas }\end{array}$ & $\begin{array}{l}\text { Um comercializa apenas } \\
\text { uvas e um comercializa } \\
\text { vinhos }\end{array}$ \\
\hline
\end{tabular}

Foram feitas notas das entrevistas, conduzidas por um guião, que também foram gravadas mediante autorização dos inquiridos. Para complementar as informações coletadas nas entrevistas, agregamos dados históricos, obtidos de artigos científicos, de documentos e relatórios. Com este procedimento, objetivamos ratificar as narrativas dos agricultores e reconstruir, de forma mais fidedigna, a trajetória evolutiva da inovação e as transformações por ela engendradas. A análise priorizou relacionar os dados com o percurso da inovação, proposto pela MLP, integrando os eventos com a ação dos atores do AKIS.

\footnotetext{
2 A abordagem empírica foi realizada no contexto do projeto AgriLink (https://www.agrilink2020.eu/), adotando, por isso, a metodologia conceitual do mesmo para a recolha de dados qualitativos e quantitativos. No presente artigo, faz-se uso apenas das informações qualitativas.
} 


\section{Resultados e discussão}

\subsection{Apresentação do caso estudado - evolução e transição para uma viticultura sustentável no Douro}

O Rio Douro, que nasce na Espanha e percorre o Norte português, empresta seu nome à região vinhateira que o circunvizinha (Figura 1). Esta região corresponde a uma das mais antigas áreas vinícolas demarcadas do mundo (Região Demarcada do Douro - RDD, reconhecida entre os anos de 1756 e 1758) (Portela \& Rebelo, 1997). Possui uma paisagem única que tornou possível, a partir de 2001, o processo de inscrição do "Alto Douro Vinhateiro" como Patrimônio da Humanidade da UNESCO (United Nations Educational, Scientific and Cultural Organization), pelo critério de "paisagem cultural evolutiva viva". O local é também caracterizado pela construção de terraços seculares, chamados socalcos, que modificaram a paisagem e tornaram viável a viticultura em encostas íngremes (mais de $40 \%$ das videiras estão em terrenos com inclinação superior a 40\% (Quaternaire Portugal/UCP, 2007). O produto vinícola dali obtido atinge 0 mercado mundial e tem como expoente o conhecido vinho do Porto (Andresen et al., 2004).

A zona possui importância também no que tange a aspectos de biodiversidade, e ali se tem observado, de forma mais generalizada a partir de 2010, o surgimento e dispersão de um conjunto de novas práticas conjugadas à viticultura. O conjunto destas práticas culmina na implantação e gestão de infraestruturas denominadas "ecológicas" (Infraestruturas Ecológicas, IEs, exemplificadas nas Figuras 2 e 3$)^{3}$ que são consideradas, para efeitos deste estudo, como uma inovação de caráter agroecológico. As IEs se expressam por uma diversidade de modos, assumindo a forma de cultivos de vegetação nativa ou exótica, em crescimento espontâneo ou propositalmente semeadas, nas entrelinhas de cultivo das videiras ou nas áreas adjacentes, com os mais diversos propósitos, como servir de corredor ecológico aos animais nativos, abrigar insetos auxiliares, ampliar a biodiversidade das áreas de cultivo, proporcionar retenção da umidade do solo, ou reduzir as perdas por erosão.

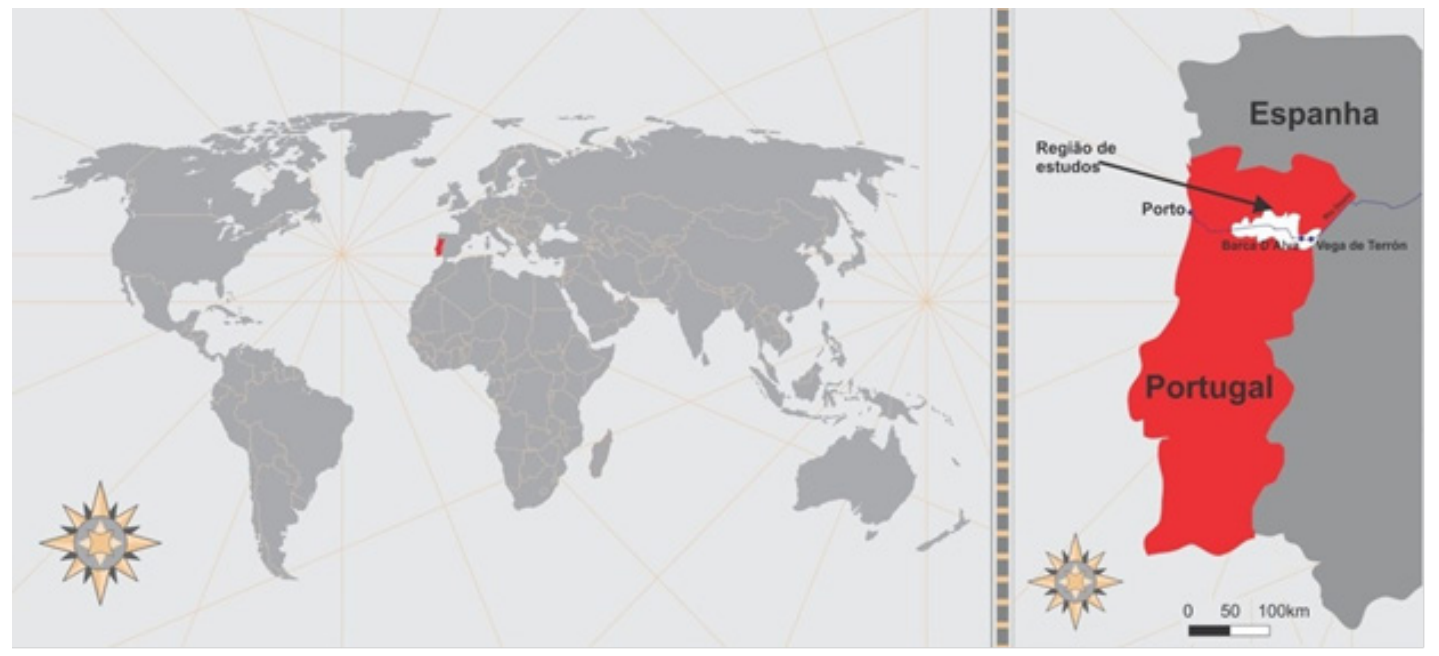

Figura 1 - Localização de Portugal, do Rio Douro e da região de estudos, no Norte português. Mapa das autoras.

${ }^{3}$ Por definição, IEs são redes de áreas naturais que desempenham papel essencial para o equilíbrio ecológico do território, contribuindo para a preservação "da vida selvagem, para a qualidade do ar e da água e para a qualidade de vida dos cidadãos" (Ferreira \& Machado, 2010, p. 1). 


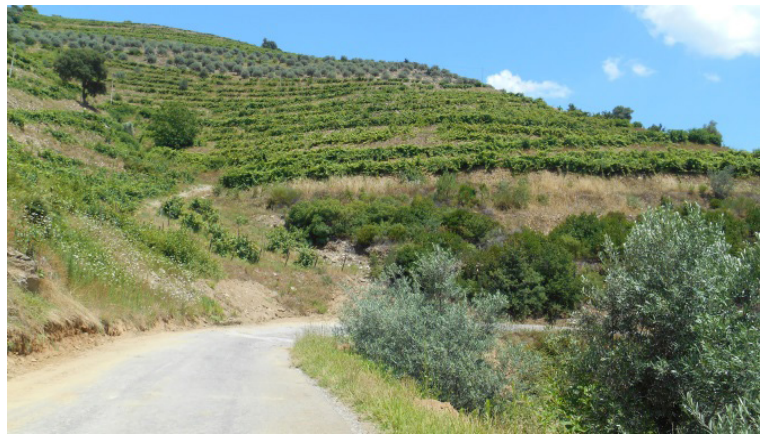

Figura 2 - Exemplificação de IEs conjugadas à vinha. Mostra a vegetação associada, tanto nos taludes, quanto nas entrelinhas de cultivo. Foto das autoras, 2018.

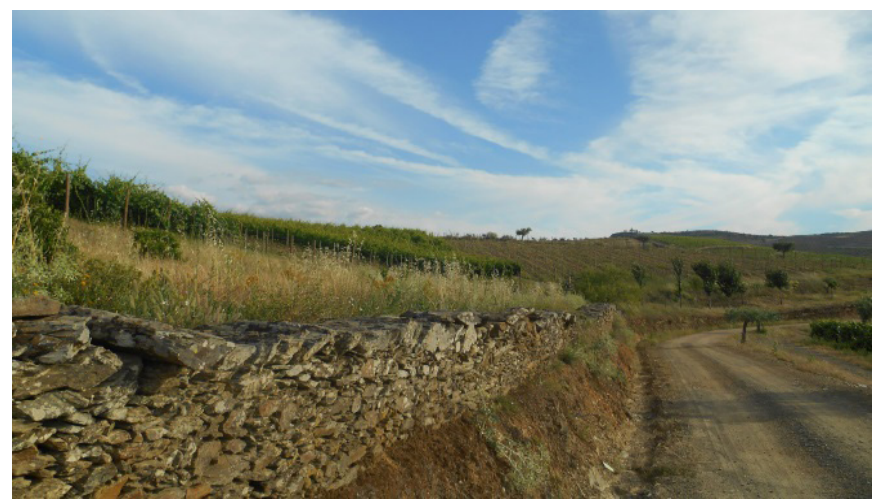

Figura 3 - Exemplificação de IEs sob a forma de um corredor ecológico perpendicular às linhas de vinha. Foto das autoras, 2018.

As informações que seguem trazem um encadeamento de fatores que se desenrolam na atual motivação dos viticultores do Douro a dinamizarem estruturas institucionais que os levaram a desenvolver estes novos métodos e técnicas, bem como a fomentar e difundir o conhecimento que subsidiou um princípio de transição, como se verá adiante.

Na história da viticultura do Douro, há de se salientar que, em meados dos anos de 1980, um conjunto de medidas denominado "Projeto de Desenvolvimento Rural Integrado de Trásos-Montes", também conhecido por sua sigla, PDRITM, promoveu profundas transformações na paisagem. O PDRITM despontou como resultado de estudos encabeçados por diversas instituições, a partir de 1974, e previa a implantação de "sistemas de plantação inovadores", com a construção de patamares altos que comportavam duas linhas de vinha e cujo objetivo era a redução de densidade de plantio. O contraponto à redução da densidade era a facilitação da mecanização, dado que à altura já se sentiam os impactos de restrição da mão de obra para o manejo dos vinhedos, bem como a incidência deste fator sobre os custos de produção. Esta modalidade de implantação das videiras levou à necessidade de reestruturação das áreas de cultivo, e, além da conversão, houve também a expansão das superfícies cultivadas (Portela \& Rebelo, 1997). Tal como seria esperado, a intensidade de novos plantios e remodelamento das áreas já cultivadas comprometeram aspectos pertinentes à biodiversidade e manutenção de recursos naturais.

No longo prazo, contudo, a mecanização dos vinhedos mostrou-se ineficiente do ponto de vista das perdas de solo por erosão, o que naturalmente já caracteriza a agricultura de encosta. Os impactos sentidos pelo PDRITM, como a intensa mobilização dos terrenos e plantio de 
novas vinhas, passaram gradativamente a ter maior controle, de forma que os elementos da paisagem não fossem mais indiscriminadamente alterados ${ }^{4}$.

É na altura dos anos de 1980 que as demandas dos viticultores por soluções técnicas e inovações calcadas nas especificidades locais faz culminar outro evento que se mostrará relevante para as transformações da viticultura e da própria inovação das IEs: o surgimento da ADVID - Associação para o Desenvolvimento da Viticultura Duriense. Em sua essência, a ADVID foi formada por um grupo de vitivinicultores que sentiu a necessidade de fomentar a investigação localizada que gerasse respostas específicas para a modernização da viticultura, aumentando a competitividade do produto local (Associação para o Desenvolvimento da Viticultura Duriense, 2020).

O despontar da ADVID é simultâneo ao crescimento mundial de produção, comércio e consumo de vinhos de elevada qualidade (os vinhos DOC - Denominação de Origem Controlada). Do que se subentende que, mediante o crescimento da concorrência internacional, os vitivinicultores do Douro sentiram a necessidade de criar estruturas que lhes dessem apoio técnico e científico para um reposicionamento de mercado. Dados do Office International de la Vigne et du Vin (1999) demonstram que nos finais da década de 1980 a superfície mundial de videiras atingiu os 10.213.000 hectares cultivados. No mesmo relatório, há referências de que a produção de uvas atingiu o seu auge entre 1981 e 1985, correspondendo a 628.084.000 quintais, seguida de um aumento da produção de vinhos que chegou à cifra dos 333.552 .000 hectolitros. É neste período que países não convencionais passam a figurar entre os maiores produtores, incluindo os EUA e a Argentina entre os cinco principais colocados, com destaque também para o Brasil, África do Sul, China e Chile, fora do eixo europeu.

No final dos anos 1990, mais um acontecimento relacionado ao desenvolvimento de formas mais sustentáveis de condução da agricultura, em Portugal, deve ser grifado, uma vez que é recorrente no discurso dos entrevistados. Diz respeito à publicação do Decreto 180/95, que passa a estabelecer o regime jurídico dos métodos de Proteção Integrada (Ptl) e Produção Integrada (Pdl) em Portugal (Direção Geral de Agricultura e Desenvolvimento Rural, 2020).

Em 2001, ocorre o tombamento do Alto Douro Vinhateiro como Patrimônio Mundial da UNESCO, pelo critério "paisagem cultura evolutiva viva”. Tal fato colocou novamente a viticultura local em evidência, já que a distinção da zona deu-se por aspectos históricos e culturais. Não só existem ali indícios arqueológicos de ocupações pré-romanas, como a presença dos socalcos vinhateiros, que são uma evidência das modificações topográficas feitas pelo homem, ao longo dos séculos, e que permitiram o cultivo nos terrenos declivosos do entorno do Douro. A expectativa, mais uma vez, era que a distinção do território contribuísse para a valorização dos vinhos locais, esperando que o mercado reconhecesse os atributos humanos, históricos e naturais únicos da região e que, com isso, o produto vinícola do local alcançasse uma maior valorização (De Aguiar, 2000).

Entre os anos de 2011 e 2015, mais uma vez mais em busca de distinção e valorização, o produto local ganha novo impulso com a criação do projeto EcoVitis - Maximização dos Serviços do Ecossistema Vinha na Região Demarcada do Douro. O EcoVitis surge a partir do intercâmbio dos viticultores do Douro com produtores estrangeiros, mas também como uma expressão da necessidade de preservar a paisagem vinhateira e a biodiversidade local. O projeto surge de consórcio institucional que teve, como promotores, a associação de vitivinicultores, a ADVID, duas empresas vitivinícolas locais e a Universidade de Trás-os-Montes e Alto Douro (UTAD). O objetivo era a valorização da paisagem pela exploração das características peculiares da

4 O PDRITM foi responsável pela conversão de 300 hectares de vinhas e implantação de 2.500 hectares de novas áreas de cultivo (Portela \& Rebelo, 1997). 
natureza, através do desenvolvimento de modelos de gestão dos vinhedos que fossem capazes de consorciar a produção com um conjunto de serviços ecossistêmicos. Além de servirem de suporte a uma produção sustentável, estes serviços ecossistêmicos deveriam facultar benefícios para o ambiente, tendo sua operacionalização a partir da introdução das IEs (Associação para o Desenvolvimento da Viticultura Duriense, 2020).

\subsection{0 caso da inovação e da transição da viticultura do Douro sob a luz dos conceitos norteadores}

Quando questionados sobre se conheciam e usavam as IEs, os entrevistados referenciaram que estas se manifestam como resultados de um conjunto de três fatores distintos, que afetaram a produção e a sustentabilidade econômica das empresas, e que se expressaram na recente decisão de adoção de novas práticas. Classificamos estes fatores de acordo com os sistemas considerados pertinentes às transições para a sustentabilidade da agricultura por Duru et al. (2015). São eles: agronômicos (pertencentes, portanto, ao sistema agrícola); ambientais (pertencente ao sistema socioecológico); e de mercado (pertencente ao sistema sociotécnico). Apresentamos esta classificação na Tabela 4.

Tabela 4 - Motivações que levaram à adoção das IEs.

\begin{tabular}{ll}
\multicolumn{1}{c}{ Fatores } & \multicolumn{1}{c}{ Referência } \\
Agronômicos/Sistema & $\begin{array}{l}\text { Os adotantes relacionaram as IEs com uma série de práticas, } \\
\text { como já anteriormente descrito, com o objetivo final de ampliar a } \\
\text { biodiversidade nas áreas de cultivo e oferecer serviços ecossistêmicos } \\
\text { às vinhas. }\end{array}$ \\
Os entrevistados relacionam as IEs também com aspectos ecológicos, \\
umbientais/Sistema \\
uma vez que no manejo destas pode haver uma combinação de \\
diferentes técnicas de gestão da vegetação nas entrelinhas de cultivo \\
e nos taludes nos arredores dos vinhedos. A vegetação ora pode \\
ser espontânea, ora propositalmente semeada, de acordo com \\
variedades de interesse, mantidas com desbastes mecânicos ou \\
deixadas em crescimento livre. Estas práticas também se relacionam \\
a uma narrativa que se tornou corriqueira nas entrevistas, que é \\
a preocupação que os agricultores têm com a redução do uso de \\
agrotóxicos. \\
Os inquiridos associaram o uso das IEs às pressões de mercado \\
que os forçam a escolher práticas mais sustentáveis, bem como à \\
presença de turistas que incentivaram a adoção das mesmas.
\end{tabular}

A primeira motivação está associada à experiência que os viticultores têm em relação à erosão (uma vez que, como se verificou, o caso reflete uma situação de agricultura de encosta). O programa PDRITM provocou uma modificação na paisagem que acabou acarretando na perda de solos, o que hoje motiva os agricultores a selecionarem suas técnicas também de acordo com este critério. As IEs, assim, aparecem como uma alternativa porque, ao revestir as entrelinhas e os taludes com as ervas, os terrenos de cultivo ganham maior cobertura, demandam menores mobilizações e ocasionam ganhos em termos de fertilidade, contribuindo para reduzir a erosão.

A segunda motivação está relacionada à adesão às medidas de Ptl e Pdl. Estas medidas conduziram os agricultores à adoção de novas posturas em relação às práticas agrícolas, obrigando-os a se comprometerem com técnicas que estivessem em consonância com uma maior estabilidade dos ecossistemas. Apesar de serem incentivados pelas regras de Ptl e Pdl a manterem a vegetação nativa, há entrevistados que não adotam as IEs. Entretanto, mesmo 
não adotando as IEs, precisam usar apenas herbicidas autorizados e expressam o desejo de erradicar totalmente o uso destes produtos ou, ao menos, dedicam esforços para reduzir o consumo. Nota-se isso por trechos das entrevistas, como os que seguem: "Os herbicidas nem deviam existir" (relato de agricultor, 69 anos, sempre trabalhou no setor agrícola e acumula experiência profissional como ex-funcionário de cooperativas vinícolas); "a televisão diz que os herbicidas fazem mal" e "na vinha que não leva herbicida, a uva tem mais qualidade" (relato de agricultor, 58 anos, sempre trabalhou na agricultura, estudou até a quarta classe). Também foi corriqueira a narrativa de que os herbicidas estão "perdendo a eficiência" e que a eliminação destes traçará o futuro da agricultura: "cada vez temos mais a consciência que temos que mudar" (relato de agricultora e Engenheira Zootécnica, na casa dos 50 anos, atuando há 23 anos no setor agrícola).

A terceira motivação relaciona-se ao fato de serem as propriedades agrícolas que lideraram a implantação das IEs as mesmas que praticam enoturismo. Com isso, recebem visitantes internacionais e foram diretamente impactadas por suas opiniões e por suas demandas de consumo. Conhecedores de exemplos de práticas sustentáveis relacionadas à viticultura mundial, estes consumidores acabaram exigindo que as vinícolas adotassem novas posturas. Sendo o vinho um produto que permite que a ele se atribuam elementos de terroir, os novos manejos vêm sendo empregados como diferenciais dos produtos, agregando valor e servindo de argumento para a venda. Esta ideia por ser percebida, por exemplo, na seguinte narrativa: "Quanto mais protegemos o meio ambiente, mais características do local se atribui ao vinho. A vegetação autóctone tem impacto sensorial sobre o vinho" (relato de Enólogo, entre 31 e 40 anos)."

Salienta-se que estas vinícolas, pioneiras na adoção de IEs, também são exportadoras e disputam, com seus vinhos, no espaço do mercado global, que inclui produtos oriundos do Novo Mundo, ainda sem uma tradição vitivinícola. A este respeito, e para compensar esta falta de tradição e fazer frente ao vinho das zonas tradicionais, incluindo o Douro, as novas regiões produtoras usam as técnicas de manejo sustentáveis como diferenciais competitivos (Brugarolas \& Rivera, 2001) e também como estratégia de marketing (Thode \& Maskulka, 1998; Wongprawmas \& Spadoni, 2018). Isto ocorre porque o vinho é capaz de expressar, em suas características, aspectos territoriais (Thomas \& Pickering, 2003), e estes aspectos convertemse em elemento estratégico ao atribuir reconhecibilidade ao produto (Scozzafava et al., 2016).

O tombamento da paisagem do Douro pela UNESCO possibilitou reforçar esta estratégia de diferenciação. Ela teve suporte na ideia de que as peculiaridades da região e dos métodos de produção poderiam ser aderidos ao produto, enaltecendo aspectos que por vezes são difíceis de replicar (Thode \& Maskulka, 1998; Wongprawmas \& Spadoni, 2018). Ao associar a historicidade da paisagem vinhateira à qualidade do vinho produzido, o Douro também adquire uma distinção, com a qual o Novo Mundo não consegue concorrer. No próprio texto da candidatura, atribuía-se a expectativa de aumentar o valor agregado graças às características paisagísticas, afirmando já na altura que a classificação e as peculiaridades da viticultura poderiam ser inovações que contribuiriam para a sustentabilidade dos negócios vitivinícolas e do enoturismo ali exercidos (De Aguiar, 2000, p. 14):

Diz respeito à autenticidade do vinho, fortemente suportada por um patrimônio genético muito rico, que sobreviveu até nossos dias, uma vez que estão repertoriadas no cadastro mais de 100 castas de videiras autóctones brancas e tintas, e que constitui uma garantia para o consumidor, último juiz da qualidade.

Por sua vez, percebemos que a não adoção das IEs está relacionada à falta de sucessão familiar das propriedades. Agricultores mais idosos, e que não possuem herdeiros interessados em dar seguimento à viticultura, não estão motivados a converter suas vinhas para que estas 
comportem as práticas de IEs. Isto porque esta inovação requer investimentos de readequação estrutural dos vinhedos para que a comportem (como corredores ecológicos ou linhas de cultivo que permitam a gestão mecanizada da vegetação na entrelinha). Além do mais, as explorações daqueles mais idosos dispõem de um menor número de trabalhadores, restrito ao casal ou membros familiares, que admitem não ter tempo suficiente para manejar as IEs. Normalmente, estes agricultores são aqueles que vendem suas uvas para as cooperativas e que são remunerados apenas pela qualidade sanitária e, até certa medida, pelo grau de refração dos frutos. Não há qualquer remuneração associada ao uso de medidas agrícolas mais sustentáveis, como redução no uso de herbicidas ou adoção de IEs. Estes viticultores também assumem não possuírem lucratividade que os permita testar a inovação, mesmo que em pequena parcela dos vinhedos, tal como têm feito as grandes propriedades, porque não querem pôr em risco as condições de sanidade da colheita, uma vez que toda a produção é considerada essencial para a sustentabilidade financeira das propriedades.

A universidade (UTAD) e a associação (ADVID), ambas com sedes dentro da RDD, foram as geradoras do conhecimento científico e técnico que ancorou o início da adoção das IEs. Esta influência deu-se por outros dois fatores: o primeiro, a formação em enologia e engenharia agronômica daqueles que hoje são gestores das explorações que implantam a inovação. Estes gestores, além de sensíveis às questões ambientais, possuem conhecimentos técnicos que lhes permitiram compreender, testar e até mesmo influenciar os agricultores a adotarem princípios agroecológicos. Segundo, sendo a associação uma entidade privada, que congrega apenas uma parte dos viticultores, aqueles que possuem condições de financiá-la são os que acabam por ter maior acesso à plenitude técnica das inovações propostas, o que causa também certa restrição à difusão dessas.

Na relação entre entrevistados e as entidades que integravam o AKIS, observa-se que o AKIS dos adotantes é mais diversificado e conta com maior número de relações com a UTAD, com outras universidades e instituições de ensino; com a ADVID; com consultores privados; com viticultores e profissionais de viticultura e enologia estrangeiros. O AKIS dos não adotantes está centrado em torno das cooperativas vitivinícolas, viticultores e enólogos locais. O que evidencia que a adoção das IEs, além de estar relacionada a motivações de diferentes tipos, está também ancorada em conhecimentos que foram buscados e construídos a partir de uma maior diversidade de relações, inclusive internacionais e com universidades.

Apesar de a universidade e associação terem gerado e divulgado materiais acerca da biodiversidade e serviços ecossistêmicos, as peculiaridades ambientais de cada propriedade demandaram que os adotantes realizassem intensos experimentos e desenvolvessem um método particular de gestão das IEs. As explorações adotantes, assim, funcionaram como nichos, e prova disso está na diversidade do emprego das IEs.

No caso do Douro, a inserção das IEs também está relacionada a um conjunto de variáveis da paisagem sociotécnica, que influenciam a criação de nichos e início de uma readequação do regime. Isto fica explicitado quando as técnicas vitivinícolas que ali evoluíram começam a provocar degradações ambientais e, com isso, o questionamento do consumidor, com consequentes constrangimentos de um comércio cada vez mais globalizado e concorrencial. Este componente de mercado da paisagem sociotécnica parece igualmente influenciar os agricultores que ainda aplicam herbicidas, mesmo que autorizados pela Ptl, já que relatam estar reduzindo o número de aplicações e o desejo de eliminar definitivamente o seu uso por conta da influência da opinião pública. Outra variável de paisagem sociotécnica que tem provocado modificações na viticultura do Douro são as alterações climáticas, que modificam o comportamento das vinhas, das próprias vegetações que compõem as IEs e, por consequência, 
do próprio produto vinícola, desafiando os gestores e agricultores em seus conhecimentos precedentes.

Contudo, mesmo entre as grandes propriedades, a instalação das IEs vem sendo gradual. É consensual que a implantação das IEs se inicia em pequenas parcelas e que, à medida que ganham conhecimentos a respeito, os agricultores expandem-na a um maior percentual de área de vinhas. Esta precaução está relacionada à sustentabilidade econômica a que estão sujeitas as grandes propriedades e reforça a caracterização das mesmas como nicho de inovação.

A inovação em questão, por englobar um conjunto de práticas de caráter ambiental, é demandante de mais mão de obra e tem neste elemento um fator reconhecidamente limitante para sua implantação e perpetuação no Douro. Mesmo aqueles que lideraram o uso das IEs, admitem que o manejo da vegetação requeira recursos humanos que parecem estar cada vez mais escassos, o que se reflete em maiores custos de produção. A demanda por maior mão de obra não é tão restritiva para algumas das grandes propriedades, que mantêm um quadro fixo de funcionários e que conseguem, assim, estabelecer um calendário de uso da força de trabalho ao longo do ano.

O cenário de alterações políticas, com a intervenção de atores nacionais e internacionais, na introdução do projeto PDRITM, das medidas agroambientais e das orientações de Ptl e Pdl, criaram um suporte institucional que igualmente sustenta a transição do regime sociotécnico. Assume-se, contudo, que no caso do Douro há um princípio de transição em uma etapa que antecede à total sobreposição das componentes sociais, técnicas, agrícolas e ecológicas da inovação às do regime. Em outras palavras, ainda não se concretizou uma completa transição porque as transições não são pontuais e envolvem vários setores ou subsetores da economia, englobando uma diversidade de atores sociais e criando uma nova estabilização, uma nova ordem no regime sociotécnico, ao longo do tempo. Para que ocorra uma transição, atores de níveis regional e nacional precisam se unir para criar novos conhecimentos, práticas, tecnologias, instituições e regras orientadoras (Sutherland et al., 2014).

Admite-se também que há evidências de que a transição esteja em seu princípio porque, mesmo os viticultores que não implementaram as IEs já perceberam as modificações na concepção da agricultura local e, em conjunto com adotantes, têm desenvolvido novos valores associados ao senso de partilha dos aspectos ambientais de uma mesma paisagem; identificação com um mesmo conjunto de problemáticas; desejos de preservação e conservação da fauna, flora, recursos hídricos e edáficos; e uma responsabilidade comungada pela entrega de um produto saudável ao consumidor. Por outro, a concepção de que há um princípio de transição em curso é reforçada pela fragilidade do processo, já que este pode retroceder por estar associado à disponibilidade de mão de obra para manter os manejos mais sustentáveis, ou, pelo menos, ao desenvolvimento de tecnologias substitutas, já que este é um fator relatado como escasso pelos entrevistados. Tal fragilidade ainda é reiterada pelas alterações climáticas, que se fazem sentir no comportamento imprevisível de todo o agroecossistema vitivinícola, desafiando agricultores e gestores em seus conhecimentos agroecológicos e tornando incerta e instável a trajetória da inovação estudada.

A Figura 4 resume o esquema de fatores, ou pressões, exercidas pelos elementos componentes da transição que foram identificados, bem como os AKIS que se relacionam à mesma. 


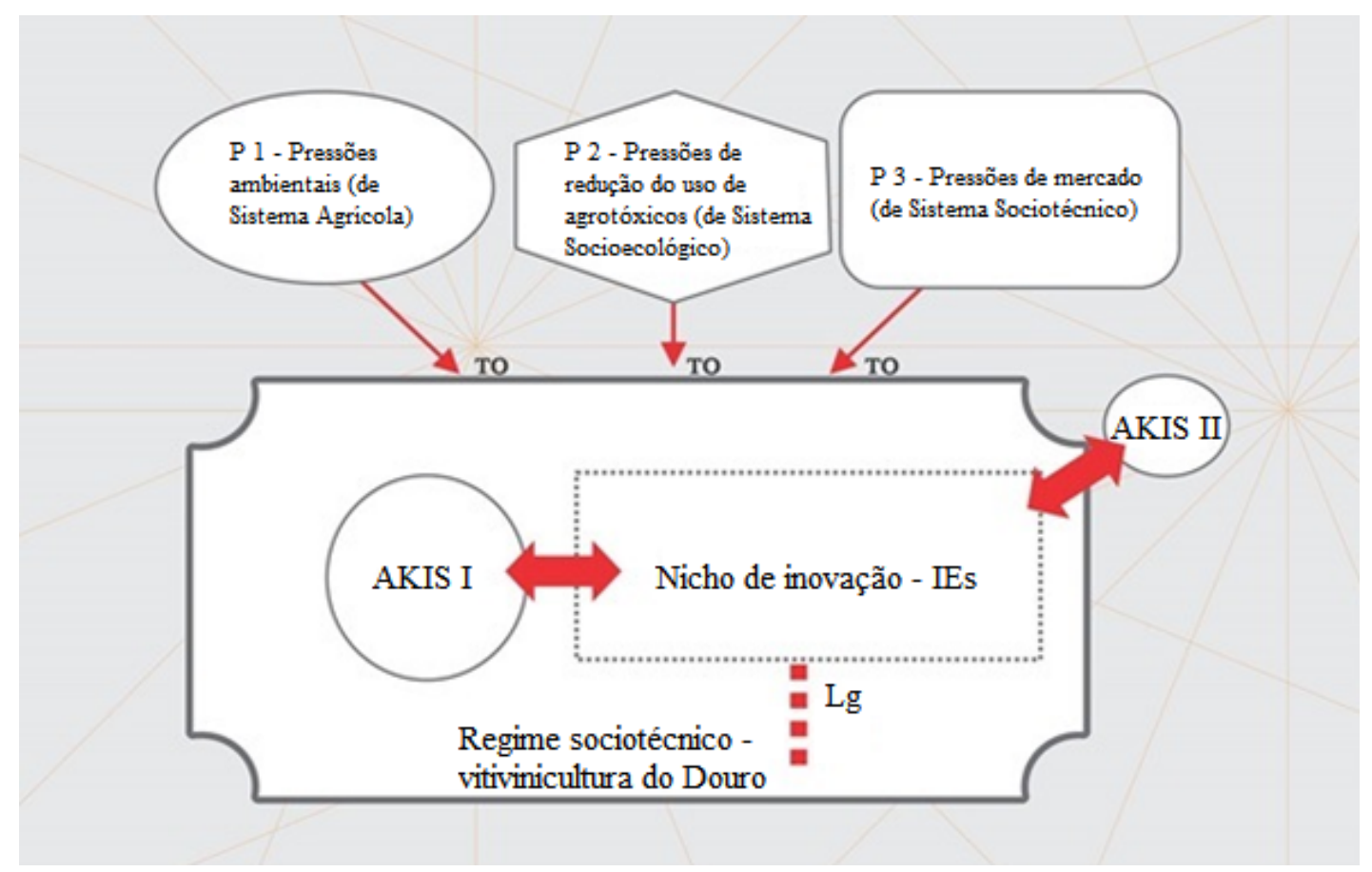

Figura 4 - Esquema representativo do princípio de transição em curso na vitivinicultura do Douro, construído com base em Elzen et al. (2012).

P1, P2 e P3 representam elementos que causam pressões sobre o regime. Cada um dos elementos possui uma forma distinta, para reforçar a ideia de que cada qual exerce um tipo de pressão;

A pressão é representada pelas setas TO, de Tensão-Oportunidade, uma vez que a pressão sobre o regime causa uma tensão em seu funcionamento, mas é também uma oportunidade de readequação deste;

O regime sociotécnico é a vitivinicultura do Douro, uma figura com bordas salientes, cujas delimitações representam peculiaridades sociais, ambientais e agrícolas;

O nicho de inovação está representado dentro do regime, uma vez que é assim que ele surge, circunscrito ao ambiente das empresas que lideraram a inovação. É uma caixa pontilhada porque troca conhecimento e inovação com os AKIS e com o próprio regime;

Lg representa a ligação entre nicho e regime, pontilhada por ainda caracterizar-se de processo tênue e que pode enfraquecer de acordo com as pressões dos elementos P1, P2 e P3 e de acordo com influências do próprio regime;

AKIS I representa as trocas de conhecimento dentro do regime, composto pelas propriedades, ADVID e UTAD;

AKIS II representa as trocas com a vitivinicultura internacional e que também influenciaram os inovadores líderes.

\section{Conclusões}

Neste artigo, mostrou-se um processo de transição para a sustentabilidade da agricultura liderado por viticultores e gestores agrícolas que atuam em escala comercial e empresarial. 0 caso, centrado no Douro, tem sua transição ancorada em um arcabouço técnico agroecológico emergente. A emergência deste processo está, por sua vez, edificada sobre uma estratégia de 
comercialização e inserção mercadológica do produto agrícola proveniente de uma agricultura de caráter corporativo que está diretamente associada às pressões de paisagem sociotécnica. De qualquer maneira, esta transição está associada a uma mudança na forma como a sociedade, neste caso representada pelo consumidor de vinhos, enxerga a agricultura e o agricultor. A primeira, como atividade econômica que também é capaz de promover serviços ambientais, e o agricultor, como um guardião dos recursos que pode ser também valorizado por este serviço.

No caso do Douro, a necessidade de inovar partiu de um grupo de viticultores sensíveis às alterações globais e que dispunham de um conjunto de condições que os permitiu mobilizar um AKIS para viabilizar e fortalecer o processo de desenvolvimento da inovação. As IEs vêm sendo implantadas com determinadas precauções devido à necessidade de sustentabilidade econômica das propriedades que paulatinamente as testam, e que assim tentam reduzir riscos que possam comprometer o futuro dos negócios. O AKIS foi dinamizado para fomentar as competências científicas e cognitivas necessárias à definição de novas trajetórias para a sustentabilidade, nos rumos de cada empresa agrícola, e atualmente estas trajetórias individuais se sobrepõem e conduzem a um princípio de uma transição territorial. Ratifica-se que a transição para a sustentabilidade demanda conhecimentos em agricultura e biologia específicos, que requerem habilidades e motivações para observação, gerenciamento, armazenamento e análise de resultados.

O nosso caso complementa a literatura científica disponível sobre as transições para a sustentabilidade da agricultura, que se tem vindo a focar essencialmente no caso das pequenas explorações agrícolas, nas inovações de base da agricultura e na agricultura que ocorre no âmbito familiar ou no seio de movimentos sociais (Ribas et al., 2007; Amekawa et al., 2010; Damasceno et al., 2011; Altieri et al., 2012; Kassie et al., 2013; Vanlauwe et al., 2014; Ilieva \& Hernandez, 2018; Bezerra et al., 2019). Enaltece que em casos como do mercado de vinhos, com caráter global, a agricultura comercial é determinante para disparar as transições. Deixa evidente que as políticas precisam criar incentivos capazes de inserir pequenos agricultores nestas dinâmicas de mercado para que possam, também eles, ter condições de responder aos movimentos da paisagem sociotécnica.

Reitera-se, entretanto, que na agricultura as transições devam ser igualmente tratadas em escala regional porque, como se verificou, são concernentes a aspectos sociais e agroecológicos locais. Sugere-se, como embasamento a futuras pesquisas, a investigação acerca dos efeitos deste princípio de transição, observada no Douro, tratando da interface entre setores, de modo também a evidenciar a vertente multidomínio das transições para a sustentabilidade (como, por exemplo, percepcionar as influências da transição da viticultura em relação ao enoturismo fomentado no local), bem como explorar a motivação para o emprego de técnicas mais sustentáveis no que tange a vinificação, por exemplo.

Do ponto de vista da MLP, sua articulação com o AKIS permitiu revelar aspectos territoriais da transição, concernentes ao âmbito de atores e do conhecimento que se dinamiza em torno da inovação. Sugerimos que a MLP deva admitir, em sua estruturação multinível, que as inovações não sejam necessariamente emergentes dos nichos sociotécnicos protegidos do mercado. A MLP também deve estar apta a representar inovações que possam emergir de dentro do próprio regime, em articulação com condições regionalmente disponíveis.

\section{Financiamentos}

A recolha de dados ocorreu no âmbito do projeto AgriLink - Agricultural Knowledge: Linking farmers, advisors and researchers to boost innovation, financiado pela União Europeia, através do programa Horizonte 2020 (Grant Agrement n 7275577). Este trabalho é financiado por 
fundos nacionais portugueses através da FCT - Fundação para a Ciência e a Tecnologia, I.P., no âmbito do projeto UIBD/04011/2020.

\section{Referências bibliográficas}

AgriLink. (2020). Agricultural knowledge: linking farmers, advisors and researchers to boost innovation. Recuperado em 27 de janeiro de 2020, de https://cordis.europa.eu/project/ rcn/210165_en.html

Altieri, M. A., Funes-Monzote, F. R., \& Petersen, P. (2012). Agroecologically efficient agricultural systems for smallholder farmers: contributions to food sovereignty. Agronomy for Sustainable Development, 32(1), 1-13.

Amekawa, Y., Sseguya, H., Onzere, S., \& Carranza, I. (2010). Delineating the multifunctional role of agroecological practices: Toward sustainable livelihoods for smallholder farmers in developing countries. Journal of Sustainable Agriculture, 34(2), 202-228.

Andresen, T., De Aguiar, F. B., \& Curado, M. J. (2004). The Alto Douro wine region greenway. Landscape and Urban Planning, 68(2-3), 289-303.

Anjos, F. S., \& Caldas, N. V. (2017). Uma resposta sólida a um regime agroalimentar em crise. O Fenômeno GAS na Itália. Revista Brasileira de Ciências Sociais, 32(95), 1-19.

Asheim, B. (1999). Interactive learning and localised knowledge in globalising learning economies. GeoJournal, 49(4), 345-352.

Associação para o Desenvolvimento da Viticultura Duriense - ADVID. (2020). Recuperado em 27 de janeiro de 2020, de http://www.advid.pt/

Bais-Moleman, A. L., Schulp, C. J., \& Verburg, P. H. (2019). Assessing the environmental impacts of production-and consumption-side measures in sustainable agriculture intensification in the European Union. Geoderma, 338, 555-567.

Benoît, M., Rizzo, D., Marraccini, E., Moonen, A. C., Galli, M., Lardon, S., Rapey, H., Thenail, C., \& Bonari, E. (2012). Landscape agronomy: a new field for addressing agricultural landscape dynamics. Landscape Ecology, 27(10), 1385-1394.

Bezerra, L. P., Franco, F. S., Souza-Esquerdo, V. F., \& Borsatto, R. (2019). Participatory construction in agroforestry systems in family farming: ways for the agroecological transition in Brazil. Agroecology and Sustainable Food Systems, 43(2), 180-200.

Biernacki, P., \& Waldorf, D. (1981). Snowball sampling: problems and techniques of chain referral sampling. Sociological Methods \& Research, 10(2), 141-163.

Brugarolas, M., \& Rivera, L. M. (2001). Comportamiento del consumidor valenciano ante los productos ecológicos e integrados. Revista Española de Estudios Agrosociales y Pesqueros, 192, 105-121.

Bui, S., Cardona, A., Lamine, C., \& Cerf, M. (2016). Sustainability transitions: Insights on processes of niche-regime interaction and regime reconfiguration in agri-food systems. Journal of Rural Studies, 48, 92-103.

Capello, R. (2017). Towards a new conceptualization of innovation in space: territorial patterns of innovation. International Journal of Urban end Regional Research, 41(6), 976-996.

Coenen, L., Benneworth, P., \& Truffer, B. (2012). Toward a spatial perspective on sustainability transitions. Research Policy, 41(6), 968-979. 
Cooke, P., Gomez Uranga, M., \& Etxebarria, G. (1997). Regional innovation systems: institutional and organisational dimension. Research Policy, 26(4-5), 475-491.

Coughenour, C. M. (2003). Innovating conservation agriculture: the case of no-till cropping. Rural Sociology, 68(2), 278-304.

Cristofari, H., Girard, N., \& Magda, D. (2018). How agroecological farmers develop their own practices: a framework to describe their learning processes. Agroecology and Sustainable Food Systems, 42(7), 777-795.

Damasceno, N. P., Khan, A. S., \& Lima, P. V. P. S. (2011). O impacto do Pronaf sobre a sustentabilidade da agricultura familiar, geração de emprego e renda no Estado do Ceará. Revista de Economia e Sociologia Rural, 49(1), 129-156.

Darnhofer, I. (2015). Socio-technical transitions in farming: key concepts. In L. A. Sutherland, I. Darnhofer, G. Wilson \& L. Zagata (Eds.), Transition pathways towards sustainability in agriculture: case studies from Europe (pp. 17-32).

De Aguiar, F. B. (2000). Candidatura do Alto Douro Vinhateiro a Património Mundial. Porto: Fundação Rei Afonso Henriques.

De Alban, J. D. T., Prescott, G. W., Woods, K. M., Jamaludin, J., Latt, K. T., Lim, C. L., Maung, A., \& Webb, E. (2019). Integrating analytical frameworks to investigate land-cover regime shifts in dynamic landscapes. Sustainability, 11(4), 1139.

Direção Geral de Agricultura e Desenvolvimento Rural - DGADR. (2020). Recuperado em 27 de janeiro de 2020, de https://www.dgadr.gov.pt/sustentavel/producao-integrada/legislacaoe-outros-documentos

Doloreux, D. (2002). What we should know about regional systems of innovation. Technology in Society, 24(3), 243-263.

Duru, M., Therond, O., \& Fares, M. (2015). Designing agroecological transitions: a review. Agronomy for Sustainable Development, 35(4), 1237-1257.

Elzen, B., van Mierlo, B., \& Leeuwis, C. (2012). Anchoring of innovations: assessing Dutch efforts to harvest energy from glasshouses. Environmental Innovation and Societal Transitions, $5,1-18$

European Union. Standing Committee on Agricultural Research - SCAR. (2012). Agricultural knowledge and innovation systems in transition: a reflection paper. Brussels: European Commission.

Feola, G., Lerner, A. M., Jain, M., Montefrio, M. J. F., \& Nicholas, K. A. (2015). Researching farmer behaviour in climate change adaptation and sustainable agriculture: Lessons learned from five case studies. Journal of Rural Studies, 39, 74-84.

Ferreira, J. C., \& Machado, J. R. (2010). Infraestruturas verdes para um futuro urbano sustentável: o contributo da estrutura ecológica e dos corredores verdes. Revista Labverde, (1), 69-90.

Geels, F. W. (2004). From sectoral systems of innovation to socio-technical systems: insights about dynamics and change from sociology and institutional theory. Research Policy, 33(67), 897-920.

Geels, F. W. (2011). The multi-level perspective on sustainability transitions: Responses to seven criticisms. Environmental Innovation and Societal Transitions, 1(1), 24-40.

Geels, F. W. (2020). Micro-foundations of the multi-level perspective on socio-technical transitions: developing a multi-dimensional model of agency through crossovers between 
social constructivism, evolutionary economics and neo-institutional theory. Technological Forecasting and Social Change, 152, 119894.

Geels, F. W., \& Schot, J. (2010). The dynamics of transitions: a socio-technical perspective. In J. Grin, J. Rotmans \& J. Schot (Eds.), Transitions to sustainable development (pp. 11-101.

Geels, F. W., Hekkert, M. P., \& Jacobsson, S. (2008). The dynamics of sustainable innovation journeys. Technology Analysis and Strategic Management, 20(5), 521-536.

Hansen, L., \& Bjørkhaug, H. (2017). Visions and expectations for the Norwegian bioeconomy. Sustainability, 9(3), 341.

Hansen, T., \& Coenen, L. (2015). The geography of sustainability transitions: review, synthesis and reflections on an emergent research field. Environmental Innovation and Societal Transitions, 17, 92-109.

Harchaoui, S., \& Chatzimpiros, P. (2019). Energy, nitrogen, and farm surplus transitions in agriculture from historical data modeling: France, 1882-2013. Journal of Industrial Ecology, 23(2), 412-425.

Hassink, J., Grin, J., \& Hulsink, W. (2018). Enriching the multi-level perspective by better understanding agency and challenges associated with interactions across system boundaries: the case of care farming in the Netherlands: Multifunctional agriculture meets health care. Journal of Rural Studies, 57, 186-196.

Hinrichs, C. C. (2014). Transitions to sustainability: a change in thinking about food systems change? Agriculture and Human Values, 31(1), 143-155.

Holtz, G., Brugnach, M., \& Pahl-Wostl, C. (2008). Specifying "regime"- A framework for defining and describing regimes in transition research. Technological Forecasting and Social Change, 75(5), 623-643.

Ilieva, R., \& Hernandez, A. (2018). Scaling-up sustainable development initiatives: a comparative case study of agri-food system innovations in Brazil, New York, and Senegal. Sustainability, 10(11), 4057.

Ingram, J. (2008). Are farmers in England equipped to meet the knowledge challenge of sustainable soil management? An analysis of farmer and advisor views. Journal of Environmental Management, 86(1), 214-228.

Isgren, E., \& Ness, B. (2017). Agroecology to promote just sustainability transitions: analysis of a civil society network in the Rwenzori Region, Western Uganda. Sustainability, 9(8), 1357.

Kassie, M., Jaleta, M., Shiferaw, B., Mmbando, F., \& Mekuria, M. (2013). Adoption of interrelated sustainable agricultural practices in smallholder systems: Evidence from rural Tanzania. Technological Forecasting and Social Change, 80(3), 525-540.

Knickel, K., Brunori, G., Rand, S., \& Proost, J. (2009). Towards a better conceptual framework for innovation processes in agriculture and rural development: from linear models to systemic approaches. Journal of Agricultural Education and Extension, 15(2), 131-146.

Konefal, J. (2015). Governing sustainability transitions: multi-stakeholder initiatives and regime change in United States Agriculture. Sustainability, 7(1), 612-633.

Lamine, C., Renting, H., Rossi, A., Wiskerke, J. S. C., \& Brunori, G. (2012). Agrifood systems and territorial development: innovations, new dynamics and changing governance mechanisms. In I. Darnhofer, D. Gibbons \& B. Dedieu (Eds.), Farming systems research into the 21st century: the new dynamic (pp. 229-255). 
Medeiros, M., \& Cazella, A. A. (2017). Cooperation networks and transformations in the food production and distribuition system of family farming in the north coast of Rio Grande do Sul, Brazil. Organizações Rurais \& Agroindustriais, 19(3), 149-159.

Moors, E., Rip, A., \& Wiskerke, J. S. (2004). The dynamics of innovation: a multilevel co-evolutionary perspective. In J. S. C. Wiskerke \& J. D. Van der Ploeg (Eds.), Seeds of transition: essays on novelty production, niches and regimes in agriculture (pp. 31-56).

Naghizadeh, R., Elahi, S., Manteghi, M., Ghazinoory, S., \& Ranga, L. (2015). Through the magnifying glass: an analyses of regional innovation models based on co-word and meta-synthesus methods. Quality \& Quantity: International Journal of Methodology, 49(6), 2481-2505.

Nygaard, I., \& Bolwig, S. (2018). The rise and fall of foreign private investment in the jatropha biofuel value chain in Ghana. Environmental Science \& Policy, 84, 224-234.

Office International de la Vigne et du Vin - OIV. (1999). Situation et statistiques du secteur vitivinicole mundial. Recuperado em 27 de janeiro de 2020, de https://www.oiv.int/public/ medias/2837/4-1-fr-stat-99.pdf

Pigford, A. A. E., Hickey, G. M., \& Klerkx, L. (2018). Beyond agricultural innovation systems? Exploring an agricultural innovation ecosystems approach for niche design and development in sustainability transitions. Agricultural Systems, 164, 116-121.

Portela, J., \& Rebelo, V. (1997). O PDRITM na RDD: contribuição para a avaliação da sua execução e dos seus efeitos imediatos. Douro: Estudos \& Documentos, /(3), 159-182.

Prost, L., Reau, R., Paravano, L., Cerf, M., \& Jeuffroy, M. H. (2018). Designing agricultural systems from invention to implementation: the contribution of agronomy: lessons from acase study. Agricultural Systems, 164, 122-132.

Quaternaire Portugal/UCP. (2007). Plano estratégico para os vinhos com denominação de origem controlada Douro, denominação de origem Porto e indicação geográfica terras durienses da Região Demarcada do Douro. Porto, Portugal: IVDP.

Ramani, S., \& Thutupalli, A. (2015). Emergence of controversy in technology transitions: Green Revolution and Bt cotton in India. Technological Forecasting and Social Change, 100(C), 198-212.

Ribas, R. P., Severo, C. M., \& Miguel, L. D. A. (2007). Agricultura familiar, extrativismo e sustentabilidade: o caso dos" samambaieiros" do litoral norte do Rio Grande do Sul. Revista de Economia e Sociologia Rural, 45(1), 205-226.

Rip, A., \& Kemp, R. (1998). Towards a theory of sociotechnical change. In S. Rayner \& E. L. Majone (Eds.), Human choice and climate change (pp. 327-399). Columbus, USA: Battelle Press.

Roberts, C., \& Geels, F. W. (2019). Conditions for politically accelerated transitions: historical institutionalism, the multi-level perspective, and two historical case studies in transport and agriculture. Technological Forecasting and Social Change, 140, 221-240.

Röling, N. G., \& Jiggins, J. L. S. (1994). Policy paradigm for sustainable farming. European Journal of Agricultural Education and Extension, 1(1), 23-43.

Scozzafava, G., Contini, C., Costanigro, M., \& Casini, L. (2016). Consumer response to quality differentiation strategies in wine PDOs. Agriculture and Agricultural Science Procedia, 8 , 107-114.

Seyfang, G. (2006). Ecological citizenship and sustainable consumption: Examining local organic food networks. Journal of Rural Studies, 22(4), 383-395. 
Sherwood, S., van Bommel, S., \& Paredes, M. (2016). Self-Organization and the Bypass: re-Imagining Institutions for More Sustainable Development in Agriculture and Food. Agriculture, 6(4), 66.

Smith, A. (2003). Transforming technological regimes for sustainable development: a role for alternative technology niches? Science \& Public Policy, 30(2), 127-135.

Sutherland, L. A., Burton, R. J., Ingram, J., Blackstock, K., Slee, B., \& Gotts, N. (2012). Triggering change: towards a conceptualisation of major change processes in farm decision-making. Journal of Environmental Management, 104, 142-151.

Sutherland, L. A., Wilson, G., \& Zagata, L. (2014). Introduction. In L. A. Sutherland, I. Darnhofer, G. Wilson \& L. Zagata (Eds.), Transition pathways towards sustainability in agriculture: case studies from Europe (pp. 1-16).

Thode, S. F., \& Maskulka, J. M. (1998). Place-based marketing strategies, brand equity and vineyard valuation. Journal of Product and Brand Management, 7(5), 58-74.

Thomas, A., \& Pickering, G. (2003). The importance of wine label information. International Journal of Wine Marketing, 15(2), 58-74.

Toffolini, Q., Jeuffroy, M. H., Mischler, P., Pernel, J., \& Prost, L. (2017). Farmers' use of fundamental knowledge to re-design their cropping systems: situated contextualisation processes. NJAS Wageningen Journal of Life Sciences, 80(1), 37-47.

Vanlauwe, B., Coyne, D., Gockowski, J., Hauser, S., Huising, J., Masso, C., Nziguheba, G., Schut, M., \& Van Asten, P. (2014). Sustainable intensification and the African smallholder farmer. Current Opinion in Environmental Sustainability, 8, 15-22.

Vila Seoane, M., \& Marín, A. (2017). Transiciones hacia una agricultura sostenible: el nicho de la apicultura orgánica en una cooperativa Argentina. Mundo Agrario, 18(37), 1-18.

Vinuto, J. (2014). A amostragem em bola de neve na pesquisa qualitativa: um debate em aberto. Temáticas, 22(44).

von Oelreich, J., \& Milestad, R. (2017). Sustainability transformations in the balance: exploring Swedish initiatives challenging the corporate food regime. European Planning Studies, 25(7), 1129-1146.

Wongprawmas, R., \& Spadoni, R. (2018). Is innovation needed in the Old World wine market? The perception of Italian stakeholders. British Food Journal, 120(6), 1315-1329. 